\title{
International policy and a universal conception of human dignity
}

\author{
Andorno, Roberto
}

DOI: https://doi.org/10.4324/9780203075005

Posted at the Zurich Open Repository and Archive, University of Zurich ZORA URL: https://doi.org/10.5167/uzh-68938

Book Section

Originally published at:

Andorno, Roberto (2013). International policy and a universal conception of human dignity. In: Dilley, Stephen; Palpant, Nathan J. Human Dignity in Bioethics: From Worldviews to the Public Square. New York: Routledge, 127-141.

DOI: https://doi.org/10.4324/9780203075005 


\section{International policy and a universal conception of human dignity}

Roberto Andorno

\section{Introduction}

This chapter aims, first, to offer a brief account of the policy statements issued by intergovernmental bodies that appeal to human dignity; second, to focus on those specifically dealing with bioethics; third, to discuss the cultural challenges that arise from the adoption of 'universal' or 'transcultural' understandings of human dignity; fourth, to attempt to respond to the objection that human dignity and human rights standards are mere products of Western culture and are therefore inapplicable to other regions of the world.

\section{Human dignity: a key concept of international human rights law}

Although the notion of human dignity has a very long history in philosophy, it has re-emerged with great vigour after the Second World War as an international legal and political concept which aims to stress the need for unconditional respect for every human being in the most different areas of social life. It was indeed in response to the horrors of that tragic period of history that the international community felt it necessary to emphasize the idea that every individual has inherent worth and accompanying rights in order to prevent "barbarous acts which have outraged the conscience of mankind" from ever happening again (Preamble of the Universal Declaration of Human Rights 1948, thereafter UDHR). Indeed, simultaneously with the end of the Second World War, the Member States of the newly created United Nations reaffirmed their "faith (...) in the dignity and worth of the human person" (Preamble of the United Nations Charter 1945). Subsequently, the UNDH served as the cornerstone of the new international human rights system which was grounded on the "recognition of the inherent dignity and of the equal and inalienable rights of all members of the human family" (UDHR, Preamble). From the very beginning, the Declaration puts forward that "all human beings are born free and equal in dignity and rights" (Article 1) and that, for that reason, "no one shall be subjected to torture or to cruel, inhuman or degrading treatment or punishment" (Article 5).

There is a widely agreed view among scholars that the emphasis on human dignity that dominates the ethical and political discourse since 1945 can be to a large extent explained by the horror caused by the revelations that prisoners of concentration camps, including children, were used by Nazi physicians as subjects of brutal experiments. In this regard, the American bioethicist Robert Baker asserts that the UDHR was in part informed by the discoveries of these abuses, which led in 1947 to the development of the Nuremberg Code by the trial that condemned the Nazi physicians. Baker claims that "the details revealed daily at Nuremberg gave content to the rights recognized by Articles 4 through 20 of the Declaration" (Baker 2001: 241-252). In other words, both modern medical ethics and international human rights law emerged simultaneously from the same tragic events and are conceptually much closer than usually assumed. Similarly, George J. Annas (2005: 160) points out that "World War II was the crucible in which both human rights and bioethics were forged, and they have been related by blood ever since."

Even if the Nuremberg Code does not explicitly include the expression 'human dignity', there is no doubt that this notion lies at the background of its ten principles, which are presented as non-negotiable. This is very significant as it puts in evidence that the idea of an unconditional human worthiness was in the mind of the judges that formulated the ten principles, and that, in their view, the rules governing medical research should be based on categorical, and not on merely utilitarian grounds. In this respect, Jay Katz (1992: 227) says that: 
"The Nuremberg Code is a remarkable document. Never before in the history of human experimentation, and never since, has any code or any regulation of research declared in such relentless and uncompromising a fashion that the psychological integrity of research subjects must be protected absolutely"(emphasis is ours).

As mentioned above, simultaneously with the development of the Nuremberg Code, the international community made an unprecedented political move with the adoption of the Universal Declaration of Human Rights, which would become the cornerstone of the international human rights system. A brief excursus into the drafting history of this founding instrument will be helpful to clarify how its intellectual authors conceived the role of human dignity. There has been long debate among scholars about the relative importance of John Humphrey and René Cassin — the Canadian and the French representatives respectively - in the drafting of the Declaration. Even if there is no doubt that Humphrey played a key role in the first draft of the document, it seems well that the incorporation of the concept of human dignity was due not to him but to Cassin, who introduced corrections to Humphrey's text. The inclusion of dignity was initially controversial, even if it had already been incorporated into the Preamble of the UN Charter. Humphrey himself considered that the reference to dignity did not add anything to his draft and that its incorporation as Article 1 of the Declaration was merely rhetoric (McCrudden 2008: 677). For others, however, it was a vital attempt to articulate their understanding of the basis on which human rights could be said to exist. In her detailed account of the history of the UDHR, Mary Ann Glendon (2002: 146) recalls how, when the South African representative questioned the use of the term dignity, Eleanor Roosevelt, who was chairing the commission that drafted the Declaration, argued that it was included "in order to emphasize that every human being is worthy of respect... it was meant to explain why human beings have to rights to begin with."

Consistently with this understanding, the two great support pillars to the Declaration, namely the International Covenant on Civil and Political Rights (ICCPR) and the International Covenant on Economic, Social and Cultural Rights (ICESCR), both of 1966, solemnly affirm that human rights "derive from the inherent dignity of the human person." Thus, human dignity is regarded in international law as the foundation of human rights; people are recognized as rights bearers because their lives and their flourishing as persons are viewed as having intrinsic worth. Actually, to talk about persons having rights would not make any sense unless moral value is previously attached to the very core of human personhood (Black 2000: 131). But dignity does not only precede human rights as their source; it also follows then as it embodies their raison d'être. Indeed, the recognition of basic rights does not have ultimately any other aim than that of securing the fundamental conditions for each human being leading a minimally good life (Nickel 1987). Therefore it can be said that rights are simultaneously grounded on dignity and aim to promote dignity.

If dignity (and not merely contingent agreement) is the foundation of human rights, then it is understandable that compliance with human rights norms is mandatory rather than discretionary. Certainly, the practical efficacy of promoting and protecting human rights is significantly aided by their legal recognition by individual states. But the ultimate validity of human rights is characteristically thought of as not conditional upon such recognition (Nickel 1987), and this is so because they are grounded on the inherent dignity of every human being. In other words, legal norms do not create individuals' rights from nothing; human rights are not the capricious invention of domestic lawmakers or of the international community, which could legitimately revoke them in a change of humour. Rather, both individual states and the international community are morally obliged to recognize that all people have basic rights (ie. that they have equally valid claims to basic goods) because they derive from the dignity which is inherent in every human being. The explicit use of the verb "to recognize" in the UDHR, which denotes the formal acknowledgment of something that already exists, is very illuminating in this respect.

It is true that human dignity is never clearly defined in international law. Such a thing would be as difficult as trying to define 'freedom,' 'justice' or whatever other key social value. In any case, this lack of definition does not entail that dignity is a merely formal or empty concept, or a purely rhetorical notion. It is not because it is too poor, but because it is too rich that it cannot be encapsulated into a definition. In reality, its core meaning is quite clear and simple and embodies a very basic requirement of justice towards people. Such requirement means, in the words of Rawls, that "each person possesses an inviolability founded on justice that even the welfare of society as a whole cannot override" (1973: 3). 


\section{Human dignity in the intergovernmental instruments relating to bioethics}

As mentioned above, the need to put some limits to research involving human subjects played a decisive role in the renewed importance of the idea of human dignity. In this regard it is very revealing that the only provision of the ICCPR which directly deals with bioethical issues is the one relating to medical research. According to Article 7, "no one shall be subjected without his free consent to medical or scientific experimentation." Twenty years after the Nuremberg Code, this article is still like an echo of that historical trial decision. More importantly, it enshrines for the first time in history the requirement of free consent for medical research in an international binding instrument.

Between the end of the 1970 s and the end of the 1990 s, the recourse to human dignity in relation to medicine went beyond the field of medical research and began to be applied to very different practices, especially those that operate at the edges of life, like abortion, embryo research, preimplantation genetic diagnosis, futile treatments, assisted suicide and euthanasia. In this varied context, it is not surprising if the term dignity was sometimes used to support different and even opposed views. Simultaneously, the concept began also to be employed to criticize what was regarded as new forms of commodification of the human body, like organ selling and surrogate motherhood.

This broad and multifaceted function of human dignity is visible in the intergovernmental instruments adopted since the end of the 90's such as the UNESCO Universal Declaration of Human Rights and Bioethics of 2005 and, at the European level, the Convention on Human Rights and Biomedicine of 1997 (also known as "Oviedo Convention"). Both instruments, which can be regarded as an extension of international human rights law into the field of biomedicine, confer on the notion of human dignity the status of an overarching principle, that is, of an ultimate and general standard that is called to guide the normative regulation of the whole biomedical field (Andorno 2009).

The UNESCO Universal Declaration of Bioethics and Human Rights of 2005 is unequivocal in this regard, as the promotion of respect for human dignity embodies not only the key purpose of the document (Article 2.c), but also the first principle governing the whole field of biomedicine (Article 3), the main argument every form of against discrimination, including for instance, genetic discrimination (Article 11), the framework within which cultural diversity is to be respected (Article 12), and the highest interpretive principle of all the provisions of the Declaration (Article 28).

The Oviedo Convention is another good example of the key role that human dignity is beginning to play in this field. The Explanatory Report to the Convention states that "the concept of human dignity (...) constitutes the essential value to be upheld. It is at the basis of most of the values emphasized in the Convention" (Paragraph 9). Recalling the history of the European document, one of the members of the drafting group recognizes that "it was soon decided that the concept of dignity, identity and integrity of human beings/individuals should be both the basis and the umbrella for all other principles and notions that were to be included in the Convention" (Kits Nieuwenkamp 2000: 329). The Preamble refers three times to dignity: the first, when it recognizes "the importance of ensuring the dignity of the human being"; the second, when it recalls that "the misuse of biology and medicine may lead to acts endangering human dignity"; the third, when it expresses the resolution of taking the necessary measures "to safeguard human dignity and the fundamental rights and freedoms of the individual with regard to the application of biology and medicine." More importantly, the purpose itself of the Convention is defined in Article 1 by appealing to the notion of human dignity.

At the end of the 1990's the notion of human dignity began also to be used with a secondary (or derivative) meaning which goes far beyond the worthiness of individuals and aims to stress the need to protect the integrity and identity of humankind as such against some potential biotechnological developments like reproductive cloning and germline interventions. These two procedures appear indeed to jeopardize basic features of the human species and our understanding of what it means to be human, in particular our interest in having an open future.

In the case of reproductive cloning, the root of the ethical problem is the total loss of biparentality (ie. the fact that every individual is conceived by the fusion of gametes of two different individuals, a male or "father", and a female or "mother"). While biparentality is a key feature of advanced animals, asexual reproduction can only be found in the most primitive living beings. It is indeed hard to see how the promotion of asexual reproduction in humans could represent a progress for humankind. Rather, it seems well that it would be the most dramatic regression in history that the human species could ever suffer. But even leaving aside the purely biological perspective, it should be noted that the element of chance that characterizes the combination - always original - of the genetic material of two progenitors has great moral relevance for the individuals themselves, as it is a precondition for a full and free self- 
discovery of one's self (Jonas 1985: 182-94). Indeed, the cloned children are to some extent deprived of such a freedom, as the "model" of their sole progenitor is - at least tacitly- imposed upon them by the mere fact that they have been deliberately conceived as a genetic copy of him or her.

The basic objection to germline interventions for enhancement purposes is similar to the one levelled against cloning. Human genetic engineering would put at risk people's freedom from deliberate predetermination of their genetic make up by third persons, and, in the long run, the principle of equality between generations. Such intergenerational freedom closely depends upon the condition that each individual's features are more due to chance than to choice, to contingency than to human design. This is definitely a paradox because the idea of a human's mastery of nature has always been regarded —at least in the Western world - as an expression of the special place of humans on earth. But when that mastery reaches the basic features of the human condition itself, then it becomes problematic and even selfcontradictory run since it entails reducing future people to the condition of an object of the subjectivity of present people; human beings are at the same time subjects and objects, and the increase of human subjectivity leads strangely to an increase of human's objectivation (Bayertz 1996: 88). Thus, it can be reasonably held that contingency in human reproduction (from which depends the non-predetermination of future people) is a value in itself that needs to be protected (Habermas 2003). This latter is an entirely novel idea in the history of moral philosophy, and stems from the awareness that the increasing biotechnological control over our own nature leads in reality not to a greater control over ourselves, but over those who will succeed us. And the exercise of such unprecedented power is in open conflict with the idea of intergenerational justice, which presupposes that the interests of future generations do not have less moral standing than the interests of present individuals.

It is important to note that the human rights framework is powerless to face these new tremendous challenges to the identity of the human species because rights only belong to existing individuals, not to humankind as such or to future generations. In this regard, it is interesting to recall that during the intergovernmental discussions that took place between 1994 and 1997 at UNESCO aiming at producing an international instrument for the protection of future generations, all references to the supposed "rights" of future generations were removed from the initial draft after the ad-hoc commission of legal experts concluded that there are not such 'rights', since this concept always relates to existing persons. The instrument that was finally adopted on 11 November 1997 was entitled "Declaration on the Responsibilities of Present Generations Towards Future Generations" and avoids any mention of the "rights" of future generations.

Therefore, it can be said that the claims sometimes made that there is a "right not to be conceived as a genetic copy of another person", or a "right to inherit non-manipulated genetic information" are more rhetorical statements than conceptually consistent arguments. Indeed, how could people who do not exist, who do not even have been conceived, be today entitled to any rights? Humankind as such, including future generations, can probably be an object of obligations of the present generation, but certainly not a holder of rights (Mathieu 2000: 43). This explains why the notion of human dignity begins to be regarded as a kind of last barrier against the deliberate alteration of the basic features that characterize our common human condition (Annas et al. 2002).

Three intergovernmental instruments illustrate this appeal to a broad understanding of human dignity to preserve the integrity of the human species: the UNESCO Declaration on the Human Genome and Human Rights of 1997, the Additional Protocol to the European Biomedicine Convention concerning Human Cloning of 1998, and the UN Declaration on Human Cloning of 2005.

The UNESCO Declaration on the Human Genome and Human Rights of 1997 provides that the human genome "is the heritage of humanity" (Article 1). This notion is inspired by the concept of 'common heritage of humanity' which aims to preserve the world's natural and cultural resources for the benefit of humankind as a whole. According to the drafters of the Declaration, when applied to the human genome, this expression means, first, that genetic research engages the responsibility of the whole of humanity and that its results should benefit present and future generations (Gros Espiell 1999: 3); second, that the international community has a duty to preserve the integrity of the human species from improper manipulations that may endanger it (Kutukdjian 1999: 33). It is also interesting to note that the 1997 Declaration directly appeals to the notion of human dignity (not to human rights) to condemn both reproductive cloning and germline interventions (Articles 11 and 24, respectively).

The above mentioned European Convention on Human Rights and Biomedicine did not address the cloning issue because the final version of the document was adopted in November 1996, a few months before the announcement of the birth of the cloned sheep Dolly, which launched a worldwide debate on this matter. In response to this gap, the Member States of the Council of Europe decided to urgently adopt a specific Additional Protocol to the Convention in order to prohibit human cloning, which was finalized 
in January 1998. The substantive reasons offered by the Protocol for the ban on human cloning are the following: a) it constitutes an "instrumentalisation of human beings," which is "contrary to human dignity" (Preamble); b) it poses "serious difficulties of a medical, psychological and social nature" for the individuals involved (id.); c) it is "a threat to human identity," because "it would give up the indispensable protection against the predetermination of the human genetic constitution by a third party" (Paragraph 3); d) it reduces human freedom because it is preferable "to keep the essentially random nature of the composition of their own genes" instead of having a "predetermined genetic make up" (id.). Regarding germline interventions, Article 13 of the Convention prohibits them on the grounds that "they may endanger not only the individual but the species itself," according to the Explanatory Report to the Convention (Paragraph 89).

Another intergovernmental instrument that is heavily drawn on a broad notion of human dignity is the UN Declaration on Human Cloning of 2005, by which Member States were called upon to adopt legal measures "to prohibit all forms of human cloning inasmuch as they are incompatible with human dignity and the protection of human life" (Paragraph d). It is interesting to see that the Declaration, which is only a two pages-document, includes no less than five explicit references to human dignity.

It is noteworthy that none of the above mentioned instruments relating to bioethics (by the way, like all major international human rights instruments) include neither a definition of human dignity, nor an explanation of the grounds for forbidding some practices that are regarded as contrary to dignity. This lack of theoretical grounding is sometimes a source of misunderstandings on the part of non-legal scholars, who see it as a failure of such policy documents. For instance, criticizing the ban on human reproductive cloning included in the UNESCO Declaration on the Human Genome and Human Rights, the philosopher John Harris writes: "the document contains not a single argument in support of this claim, nor any indication as to just what is meant by human dignity" (2008: 305). This kind of criticisms represent a mistake about the nature of international policy documents, which are not philosophical treatises aimed at discerning the truth so much as political statements resulting from compromise (Baylis 2008: 323-39). In other words, intergovernmental instruments dealing with bioethics (or with whatever other issues) should not be assessed with purely academic criteria because they belong to another realm of human activity; they are not mainly a product of academic work, but rather a kind of compromise between a theoretical conceptualization made by experts and what is practically achievable given the political choices of governments (Andorno 2007). After all, the law has an eminently practical, not theoretical purpose; it aims to crystallize the existing consensus about a particular policy option in order to promote the common good, and not to define the ontology of things, nor to provide an ultimate theoretical justification of the choices made.

\section{Is a universal understanding of human dignity compatible with cultural diversity?}

Since the end of the Second World War, a universal understanding of human dignity goes hand in hand with the universality of human rights. Before 1945, the language of rights merely existed on the country specific level. Despite the unquestionable political and intellectual impact of the eighteenth century declarations of natural rights such as the American and French declarations, the dominant tendency was that of a merely contractual legal account of rights that resulted in positive law. With the creation of the United Nations in 1945 and the adoption of the UDHR and other subsequent international human rights instruments, the contractual account of rights was to some extent replaced with the idea of rights as universal moral standards necessary for human flourishing.

As noted above, human dignity is presented in this new context as the foundational notion of rights, that is, as the ultimate rationale for the recognition of equal rights to every human being regardless of ethnic origin, nationality, social status, religion, sex, age, or any other particular feature. Human dignity and human rights are regarded as universal by definition, since they are attached to every human being qua human. If human rights were not universal, they were not human rights at all. It is noteworthy that human dignity and human rights could not even been thought if they were not understood as universal.

Certainly, respect for human dignity and human rights rests upon the belief in the existence of a truly universal moral community comprising all human beings; it assumes that there are some moral truths that transcend boundaries between countries and cultures. Such respect embodies the conviction that "there are some things that should not be done to anybody, anywhere" (Midgley 1999: 160), or, according to Dworkin (1994: 236), that people must "never be treated in a way that denies the distinct importance of their own lives." This categorical nature of human dignity raises the question whether it is compatible with respect for cultural diversity or whether both values are necessarily opposed. 
My view on this is that human dignity and cultural diversity are not only 'compatible', but that dignity is the necessary precondition for the prima facie moral duty to respect the cultural specificities of each society. If every individual would not have any inherent (ie. universal) worthiness, how then could the particularities of the community he or she belongs to be worthy of respect? If a universal understanding of human dignity were wrong because of its universal character, then how could the principle of respect for other cultures (which is itself a universal principle) be justified?

At this point it is helpful to remind that, contrary to what is sometimes asserted, cultural diversity and the existence of different moral standards are not at all new phenomena, but are as old as humanity. Ancient philosophers like Plato and Aristotle were perfectly aware of the existence of different and even opposed moral codes. Moreover, their search for universal ethical criteria emerged precisely as a consequence of the awareness of cultural diversity, not ignoring it; different moral views acted on them as a strong incentive to think about the objectivity of morality, and to try to discover the objective goods that may guide moral behaviour (Spaemann 1991: 14).

At the same time, it should be emphasized that universal principles (ie. human dignity and human rights) do not need to be understood as rigid ones, but rather as standards that are flexible enough to be compatible with respect for the specificities or each culture. As a matter of fact, the human rights system allows some local variations, not in the substance, but in the form in which particular rights are implemented (Donnelly 1989: 109-42).

Of course, it may happen that human rights and certain practices that could be seen as cultural traditions of a particular society are in conflict. In such cases, human rights must prevail. Practices such as inhuman or cruel punishments (ex. lapidation), female genital mutilation, child labour, the so-called "honour killing" of women who are regarded as having brought dishonour upon the family, and discrimination against people of lower castes, even if accepted by large part of a particular community, are seriously incompatible with most basic human rights and therefore do not deserve to be given due regard on the ground that they reflect the cultural specificities of that society. This is clear not only in international human rights law in general, but also in the specific field of bioethics: the UNESCO Universal Declaration on Bioethics and Human Rights of 2005 is a good example of this; while recognizing in Article 12 that cultural diversity should be given "due regard," the Declaration makes it clear that its respect is subjected to the condition that it is not "contrary to human dignity, human rights and fundamental freedoms."

Thus, cultural diversity is not a synonymous for cultural relativism. Cultural diversity is a fact; cultural relativism is a theory about morality. Cultural diversity is a value in itself as it puts in evidence how societies develop differently across time and space depending on their specific historical circumstances, environmental factors, traditions, religion, etc. All these specificities lead to significant variations in the way societies organize themselves, and also in the way they conceptualize ethical norms and values. The cultural particularities of every society are worthy of respect, because they make part of its own identity and self-understanding. Far from necessarily being a source of conflict or tension between societies or ethnic groups, they are a precious asset of humankind that deserves to be preserved against the risks of a cultural homogeneization.

On the other hand, cultural relativism claims that morality is merely a product of culture, and for this reason there are no objective moral truths, but only truths relative to specific cultural settings. According to this view, a practice may be good in one cultural setting and bad in another, but there are no practices that are intrinsically good or intrinsically bad; thus, there are no universal truths in ethics; the customs of each society is all that exist. Yet, cultural relativism is not as plausible as it may appear as a first sight. To show this it is helpful to consider the syllogism which is at the background of cultural relativistic positions (Rachels 1993):

- Different cultures have different moral standards (Premise 1)

- All standards cannot be simultaneously right (Premise 2)

- Therefore, there is no objective moral truth in morality (Conclusion)

It is not hard to see that the conclusion does not logically follow from the premises. Even if the premise 1 is true (or true to some extent), the conclusion might be false because it deals with totally different matters. Premise 1 concerns what people think or believe (in some societies, people believe one thing; in other societies people believe something else; in some societies, people may think that degrading treatment of individuals of lower castes is right, in other societies, people may think that that practice is wrong). But the conclusion attempts to say something, not about what people think, but about what really is the case. In other words, from the mere fact that people may disagree about the rightness or wrongness 
of a particular behavior (premise 1) does not follow that there is no objective truth in morality (conclusion); it could perfectly be that some practices are objectively wrong, and that the views supporting them are simply mistaken.

\section{Is the promotion of human dignity and human rights a form of Western cultural imperialism?}

One of the most common objections to the very idea of human dignity and human rights applying universally is that they embody a Western liberal-individualistic perspective and are therefore alien to other cultures. Attempting to impose respect for human rights standards on non-Western countries would be tantamount to cultural imperialism. This argument has also been made in the specific field of bioethics to object the human rights approach adopted by intergovernmental bodies. For instance, commenting on the UNESCO Universal Declaration on Human Rights and Bioethics of 2005, some scholars criticize the document on the ground that "human dignity and human rights, both strong features of European enlightenment philosophy, pervades this Declaration" (Schuklenk and Landman 2005).

Although the philosophical controversy between universalists and relativists is too complex to be adequately covered in this chapter, some responses to above mentioned objection are immediately available. First of all, it is true that the current notion of human rights has its immediate origins in the insights of the European Enlightenment philosophers and in the political revolutions of the end of the eighteenth century, notably, the American and French Revolutions. However, this historical circumstance is not a good enough reason to discard the idea that people have inherent dignity and equal rights, just as it would not be enough to argue that Mozart or Bach were Europeans to deny the extraordinary beauty of their works. The relevant question is whether or not the notion that every human being has inherent dignity and rights makes sense and deserves to be promoted, no matter where this idea was conceptually developed. It can even be claimed that the current widespread conviction, well enshrined in international law, that people have basic rights simply by virtue of their humanity, and irrespective of ethnic origin, sex, nationality, religion, or social and economic status, is one of the major achievements of modern civilization, much more important than any scientific or technical development (Andorno 2007). In a few words, merely pointing to moral diversity and the presumed integrity of individual cultures does not, by itself, provide a philosophical justification for cultural relativism or a sufficient critique of universalism.

It is indeed paradoxical that the most severe criticisms of the universality of human rights come from Western scholars. In this regard, the Indian-born economist and philosopher Amartya Sen (1998 40-3) points out that those criticisms are often based on a misconception of non-Western (largely Asian) societies, as if people in these countries had little or no interest in their rights and were only concerned with issues of social order and discipline (misconception which is of course well exploited by authoritarian regimes). In confirmation of Sen's remark, it is interesting to mention that the main weakness that some Asian bioethicists see in the 2005 UNESCO Declaration is not the adoption of a human rights approach, but precisely the opposite: the fact of not having emphasized enough the universality of human dignity and human rights...! (Jing- Bao 2005; Asai and Oe 2005).

In addition, it should not be forgotten that, after all, international human rights law has been developed along the last six decades by representatives of the most diverse countries and cultures and therefore it is hard to claim that it intends to impose one cultural standard. Rather, it can be said that it seeks to promote a minimum legal standard of protection for all people in our common world. As such, universal human rights can be reasonably seen as the "hard-won consensus of the international community," and not as the cultural imperialism of any particular region or set of traditions (AytonShenker 1995: 2).

The previous remarks do not intend to ignore the fact that in many Western nations there has been an excessive emphasis on rights and freedoms for the individual, sometimes to the detriment of family and community values, which are of paramount importance to most non-Western (mainly Asian and African) societies. However, it would be equally fair to say that international law has made substantial efforts over the last decades to be more attuned to the communal and collective basis of many non-Western countries. This was done, in particular, through the development of the 'second generation of rights' that are included in the abovementioned International Covenant on Civil and Political Rights, such as the right to education, the right to a fair remuneration, the right to healthy working conditions, the right to health care, the protection of the family and children, etc. This tendency toward a broader understanding of human rights has been even further developed with the 'third generation of human rights,' the so-called 'rights of solidarity,' which include the right to development, to peace, to self-determination, and to a healthy environment. This is to say that, although human rights remain philosophically grounded within an individualist moral doctrine, there can be no doubt that serious attempts have been made by the 
international community to adequately apply them to more communally oriented societies (Andorno 2009).

In any case, the truth is that today the objections to the universality of human rights have lost much of their practical significance because virtually all states accept the authority of international human rights law. The six core international human rights treaties (on civil and political rights, economic, social, and cultural rights, racial discrimination, women, torture, and children) have an average 166 ratifying states, which represents a truly impressive $85 \%$ ratification rate (Volodin 2009: 16-24).

\section{Conclusion}

Since 1948, the notion of human dignity operates as a central organizing principle of the international human rights system. It not only plays a foundational role by offering the ultimate reason why do people have rights, but also helps identifying those practices that are unacceptable as they entail treating people in a way that denies the distinct importance of their lives, or instrumentalize them in a way that imply using them as mere means to another's ends.

Regarding bioethical issues, respect for the dignity of every individual has acquired in the last decade the status of an overarching principle which is called to guide the whole biomedical field. By the end of the 1990s, it began also to be used with a secondary or extended meaning, which relates to the integrity and identity of humankind as such and to the promotion of intergenerational justice.

Certainly, there is no always unanimity between countries (and within each country) about the concrete implications of human dignity, especially regarding those medical practices that operate at the edges of life. However, divergent results in the most controversial issues may not necessarily mean that a universal conception of dignity does not exist, but suggest only that a universal understanding of dignity does not exist at the margins (McCrudden 2008: 711).

This paper has basically tried to demonstrate that human dignity and human rights, which are by definition universal, are not in conflict with respect for cultural diversity, and that this is also valid in the field of bioethics. The circumstance that bioethical issues are closely linked to the deepest socio-cultural and religious values of every society is not an obstacle to the formulation of universal principles. Quite the contrary. Precisely because bioethics is close to the most cherished aspirations of people, and since people are essentially the same in the US and in Guinea, in France and in Japan, it is not that difficult to develop some minimal common standards. Human dignity plays in this regard a unifying role by reminding that all human beings are entitled to some basic goods, and that there are things that should not be done to anybody, anywhere. From this perspective, dignity is the most valuable bridge between cultures that we have.

\section{Bibliography}

Andorno, R. (2007) 'Global bioethics at UNESCO: In Defence of the Universal Declaration on Bioethics and Human Rights', Journal of Medical Ethics, 33: 150-154.

Andorno, R. (2009) 'Human Dignity and Human Rights as a Common Ground for a Global Bioethics', Journal of Medicine and Philosophy, 34(3): 223-40.

Annas, G.J. (2005) American Bioethics. Crossing Human Rights and Health Law Boundaries, New York: Oxford University Press.

Annas, G.J., Andrews, L. and Isasi, R. (2002) 'Protecting the endangered human: Toward an international treaty prohibiting cloning and inheritable alterations', American Journal of Law and Medicine, 28(23):151-178.

Asai A, and Oe S. (2005) 'A valuable up-to-date compendium of bioethical knowledge." Developing World Bioethics (Special Issue: Reflections on the UNESCO Draft Declaration on Bioethics and Human Rights), 5(3):216-9.

Ayton-Shenker, D. (1995) 'The challenge of human rights and cultural diversity: United Nations background note'. New York: United Nations Department of Public Information. Available: http://www.un.org/rights/dpi1627e.htm (accessed 31 July 2010).

Baylis, F. (2008) 'Global Norms in Bioethics. Problems and Prospects', in: R. Green, A. Donovan, and S. Jauss (eds), Global Bioethics. Issues of Conscience for the Twenty-First Century, Oxford: Clarendon Press, pp. 323-39.

Baker, R. (2001) 'Bioethics and Human Rights: A Historical Perspective', Cambridge Quarterly of Healthcare Ethics, 10(3): 241-52. 
Bayertz, K. (1996) 'Human Dignity: Philosophical Origin and Scientific Erosion of an Idea', in: K. Bayertz (ed.), Sanctity of Life and Human Dignity, Dordrecht: Kluwer, pp. 73-90.

Black, V. (2000) 'What Dignity Means', in: E. McLean (ed.), Common Truths: New Perspectives on Natural Law, Wilmington, DE: ISI Books, pp. 119-50.

Donnelly, J. (1989) Universal Human Rights in Theory and Practice, Ithaca, NY: Cornell University Press.

Dworkin, R. (1994) Life's Dominion. An Argument About Abortion, Euthanasia and Individual Freedom, New York: Vintage.

Glendon, M.A. (2002) A World Made New. Eleanor Roosevelt and the Universal Declaration of Human Rights, New York: Random House.

Gros Espiell, H. (1999) 'Introduction' in: UNESCO's Division of Ethics of Science and Technologies (ed.), Genèse de la Déclaration universelle sur le génome humain et les droits de l'homme, Paris: UNESCO, pp. 1-9.

Habermas, J. (2003) The Future of Human Nature, Cambridge: Polity Press.

Harris, J. (2008) 'Global Norms, Informed Consent, and Hypocrisy in Bioethics', in: R. Green, A. Donovan, and S. Jauss (eds), Global Bioethics. Issues of Conscience for the Twenty-First Century, Oxford: Clarendon Press, pp. 297-322.

Jing-Bao N. (2005) 'Cultural values embodying universal norms: A critique of a popular assumption about cultures and human rights'. Developing World Bioethics (Special Issue: Reflections on the UNESCO Draft Declaration on Bioethics and Human Rights), 5(3):251-7.

Jonas, H. (1985) Technik, Medizin und Genetik. Zur Praxis des Prinzips Verantwortung, Frankfurt: Insel.

Katz, J. (1992) 'The Consent Principle of the Nuremberg Code: Its Significance Then and Now' in: G.J. Annas and M.A. Grodin (eds), The Nazi Doctors and the Nuremberg Code, New York: Oxford University Press, pp. 227-39.

Kits Nieuwenkamp, J. (2000) 'The Convention on Human Rights and Biomedicine', in: J. Dahl Rentdorff and P. Kemp (eds), Basic Ethical Principles in European Bioethics and Biolaw, vol. II, Guissona (Catalonia): Barnola, pp. 325-340.

Kutukdjian, G. (1999) 'Institutional Framework and Elaboration of the Revised Preliminary Draft of a Universal Declaration on the Human Genome and Human Rights', in: M.G.K Menon, P.N. Tandon, S.S. Agarwal and V.P. Sharma (eds.), Human genome research: emerging ethical, legal, social, and economic issues, New Delhi: Allied Publishers.

Mathieu, B. (2000) Génome humain et droits fondamentaux, Paris: Economica.

McCrudden, C. (2008) 'Human Dignity and Judicial Interpretation of Human Rights', The European Journal of International Law, 19(4): 655-724.

Midgley, M. (1999) 'Towards an ethic of global responsibility', in: T. Dunne and N. J. Wheeler (eds), Human Rights in Global Politics, Cambridge: Cambridge University Press.

Nickel, J. (1987) Making Sense of Human Rights: Philosophical Reflections on the Universal Declaration of Human Rights, Berkeley: University of California Press.

Rachels, J. (1993) 'The Challenge of Cultural Relativism' in: J. Rachels (ed.), The Elements of Moral Philosophy, New York: McGraw-Hill, pp. 22-36.

Rawls, J. (1973) A Theory of Justice, Oxford: Oxford University Press.

Schuklenk, U. and Landman, W. (2005) 'From the Editors', in: Developing World Bioethics. Special Issue: Reflections on the UNESCO Draft Declaration on Bioethics and Human Rights, 5(3):iii-vi.

Sen, A. (1998) 'Universal Truths: Human Rights and the Westernizing Illusion', Harvard International Review, 20(3): 40-3.

Spaemann, R. (1991) Moralische Grundbegriffe, Munich: Beck.

Volodin, V. (ed.) (2009) Human rights. Major international instruments. Status as at 31 May 2009. Paris: UNESCO. Available: http://unesdoc.unesco.org/images/0018/001834/183452m.pdf (accessed 31 July 2010). 